\title{
THE MATING SYSTEM OF MYDAS VENTRALIS (DIPTERA: MYDIDAE)
}

\author{
By John AlcocK* \\ Department of Zoology, Arizona State University \\ Tempe, AZ 85287-1501
}

\section{INTRODUCTION}

The mydid flies are a little studied group, particularly with respect to mating biology (Cole, 1969). Males of the giant Brazilian Mydas heros, reputedly the largest of flies, are territorial at earthen mounds made by Atta ants (Zikan, in Wilcox and Papavero, 1971). Females oviposit in the nests of these ants and males capture mates at these sites. Territorial residents drive rivals away so that one male per mound is the rule. This account suggests a form of resource defense polygyny (Emlen and Oring, 1977), with males guarding the oviposition resource as a means of gaining access to mates. However, female defense polygyny is also a possibility if males are territorial to contact virgin females emerging from nest mounds, rather than gravid females drawn to oviposition sites.

In contrast, males of $M$. xanthopterus defend perching areas on mountaintops in southeastern Arizona where they pursue a wide variety of flying insects. Although Nelson (1986) did not observe any matings, he found no evidence that the territories contained oviposition or emergence sites or any food that females might use. Nelson suggested that this species exhibits a hilltopping or landmark defense mating system. Cases of this sort do not involve territoriality at resources that females need, merely defense of sites that are visited by females solely for the purpose of acquiring a mate (Shields, 1967; Alcock, 1987).

This paper provides an account of the natural history of males of $M$. ventralis Gerst., a species that engages in hilltopping behavior in central Arizona. I then compare the mating system of this mydid fly with that of other hilltopping species.

\footnotetext{
*Manuscript received by the editor August 6, 1989.
} 


\section{Methods}

The location of the study was Usery Peak (elevation $901 \mathrm{~m}$ ), Maricopa County, Arizona in the upland Sonoran Desert. The flies were observed on five days between 17-22 June 1984, four days between 10 June to 29 July 1987, and on 21 days, 20 of which occurred in four 5-day blocks, in the period from 13 June to 20 July 1989. Individuals $(N=115)$ were captured and marked on the thorax or wings with dots of Liquid Paper Typewriting Correction Fluid. The wing length of 77 of the marked flies was taken with vernier dial calipers accurate to $0.05 \mathrm{~mm}$. I monitored the activity of 20 marked males for $30 \mathrm{~min}$ each to record the frequency and nature of their interactions with others.

\section{RESULTS}

Territorial behavior

Males of $M$. ventralis were present on Usery Peak from as early as 0620 until as late as 1020 M.S.T. The peak itself consists of a long scalloped ridge ( $175 \mathrm{~m}$ in length) with four prominent high points. With few exceptions, males occupied only these elevated positions. When at a high point, the flies spent the vast majority of their time perched on the ground, or on rocks, or on exposed twigs, leaves, or spines of desert plants, including cacti (Fig. 1) and shrubs, at a height of a meter or less. From their perches, they occasionally sallied out after passing insects, including conspecifics but also scoliid and pompilid wasps, and even dragonflies, bombyliid flies, cicadas and birds. If the passing object was not another mydid fly, the pursuing male soon turned back to land again, often on or near the perch from which it left. Chases of this sort occurred at the rate of $5.4 \pm 4.8$ per $30 \min (\mathrm{N}=20)$.

In addition, males regularly engaged in spontaneous patrol flights, in which they circled around an area roughly 5 to $10 \mathrm{~m}$ in diameter. These flights took place at the rate of $2.4 \pm 2.2$ per $30 \mathrm{~min}$ $(\mathrm{N}=20)$.

Interactions between conspecific males took two forms: (1) relatively slow chases in which the two males looped around each other in circles and (2) faster, straight-line chases, with one male directly behind the other, sometimes striking the leader in flights that typically took the two flies dozens of meters downhill. In cases of 


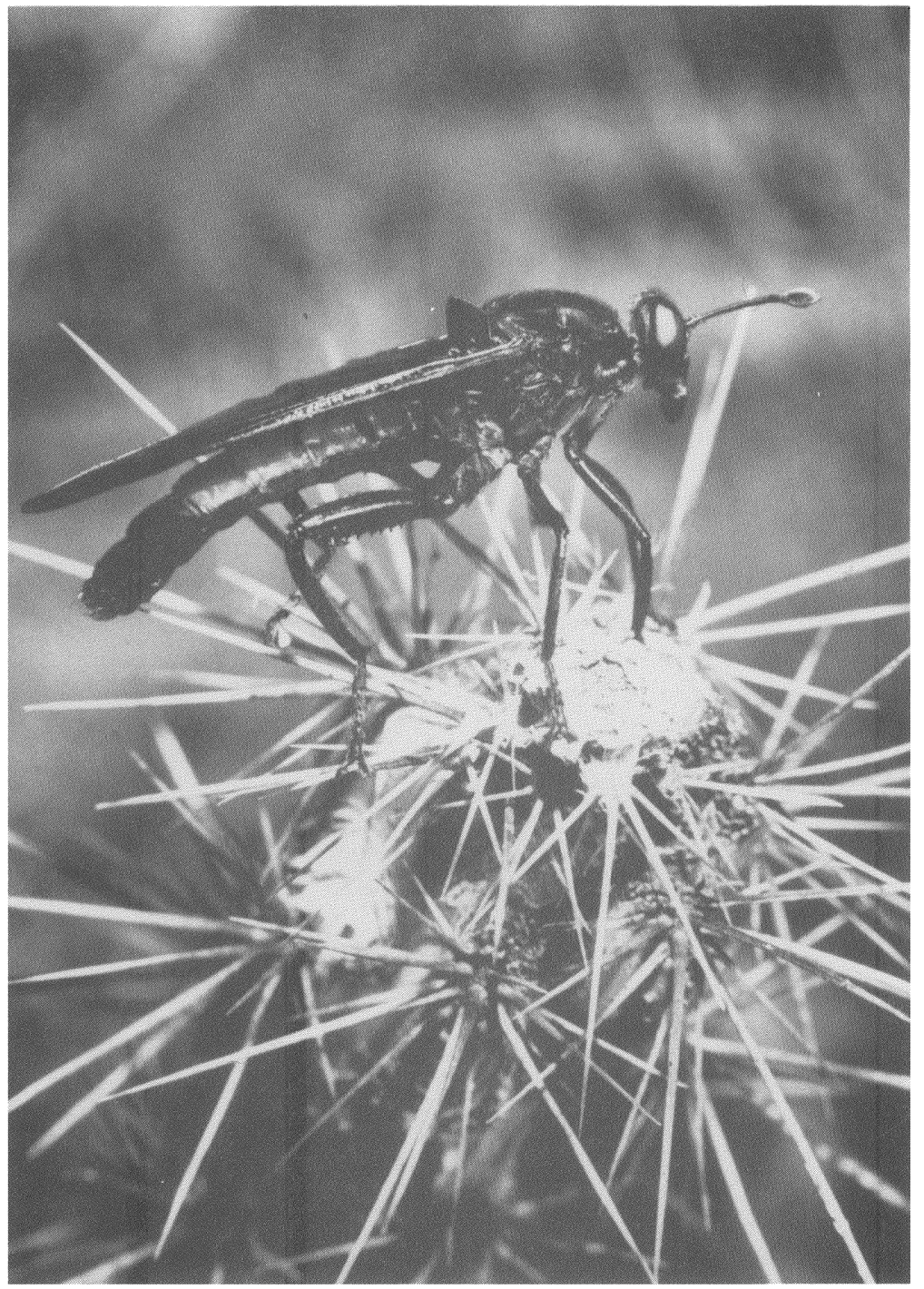

Fig. 1. A male of Mydas ventralis perched on a staghorn cactus on Usery Peak. 
looping flights, the two males remained on the hilltop together; downhill chases ended with the return of one male and the departure of the other. Encounters of either sort with conspecifics were infrequent ( $1.3 \pm 1.6$ per $30 \mathrm{~min}, \mathrm{~N}=20)$.

The usual effect of a male's downhill chases was to drive off conspecific intruders. Even when two males were present in the same general area they tended to perch at least $5 \mathrm{~m}$ apart. Therefore, males of $M$. ventralis appear to exhibit a moderate degree of territorial defense of a landmark perch site.

Site tenacity

Most males returned to their perching site after being marked and released. Of 15 flies marked in 1984 and 1987, 11 (73\%) returned on the day on which they had been captured. Of the 100 males marked during 1989, 64 were seen again on the peaktop on the day when they were marked. Many circled about the perching area and landed within seconds of their release. The mean duration between release and last sighting on the day of marking for a sample observed between 24 June and 16 July was $54.5 \pm 37.5 \mathrm{~min}$ (maximum $=145$ $\mathrm{min} ; \mathrm{N}=47$ males that stayed on the peak for at least $5 \mathrm{~min}$ ).

However, day-to-day site tenacity was much less pronounced. In 1984 and 1987, four $(26 \%)$ of 15 marked males were seen on more than one day; in 1989 just $15(20 \%)$ of 75 males were seen on a day other than the one on which they were marked. $(N=75$ for the 1989 sample because 25 males were marked on days that were not immediately followed by another day of observation.) The maximum interval between marking and last sighting was seven days and only two males were seen on more than two days during the study.

Furthermore, even on the days when a male was in residence at Usery Peak he often moved between several of the four favored perching areas along the ridgeline. In 1989 I collected 26 records of males shifting perch sites during one morning's observation, and this surely underestimates the frequency of such shifts given that I censused the ridgeline irregularly and never more than five times in a morning.

Body size and male behavior

Males of $M$. ventralis are highly variable in body size, with winglengths ranging from 1.55 to $2.8 \mathrm{~cm}$. Because they appear to interact aggressively, we can examine the hypothesis that body size influ- 
ences the ability of males to hold territories by comparing the average size of males that returned after being marked versus those that were not seen again. The assumption here is that established territory owners should be more likely to return than intruders or transients that I happened to capture. There was, however, no difference in the mean wing-length of males that returned after marking $(\overline{\mathrm{x}}=2.36 \pm 0.27 \mathrm{~cm}, \mathrm{~N}=47)$ and the mean for males that fled after marking $(\overline{\mathrm{x}}=2.35 \pm 0.21 \mathrm{~cm}, \mathrm{~N}=30 ; \mathrm{t}=0.12, \mathrm{P}>0.50)$.

Nevertheless, if large males can defend their perching areas better than small ones, then the length of time between first and last sighting on a morning should be positively correlated with the winglength of the males. However, there was no siginificant correlation between residence time and body size (Spearman's rank correlation coefficient $=-0.16, P>0.05, N=47)$. Nor were males that returned for another day on the peak larger than average $(\bar{x}=2.29 \pm 0.39$ $\mathrm{cm}, \mathrm{N}=7$ ). Large body size apparently confers no competitive advantage in male-male interactions in $M$. ventralis.

\section{Mating behavior}

In 1984 and 1987 three copulations were observed at 0725, 0730 and 0840 MST. All followed this sequence: A perched male flew out to meet an incoming female, which he grasped in the air. While flying in a mounted position the male coupled and then turned $180^{\circ}$. Facing away from each other, the pair remained airborne as they travelled downslope away from the ridgeline rendezvous site some 25-50 m before alighting at the base of or within the foliage of an ocotillo (Fouquieria splendens), jojoba (Simmondsia chinensis), or palo verde (Cercidium microphyllum) (Fig. 2).

An additional twelve copulations were observed during the 1989 field season at times between 0730 and 0900 M.S.T. All but one followed the pattern just described. The exception occurred when a male that had completed mating and had returned to his hilltop perch flew back after a few minutes to the jojoba bush where he had left his mate. The male found the female still there and he mounted her while she perched in the foliage of the bush; copulation ensued although for what time is unknown.

The duration of four copulations lasted more than $30 \mathrm{~min}$ but less than $1 \mathrm{hr}$ with two complete matings exactly timed at 59 and $54 \mathrm{~min}$.

Two of the twelve copulations in 1989 involved a captured female that I netted on the ground at one of the four high points on the 


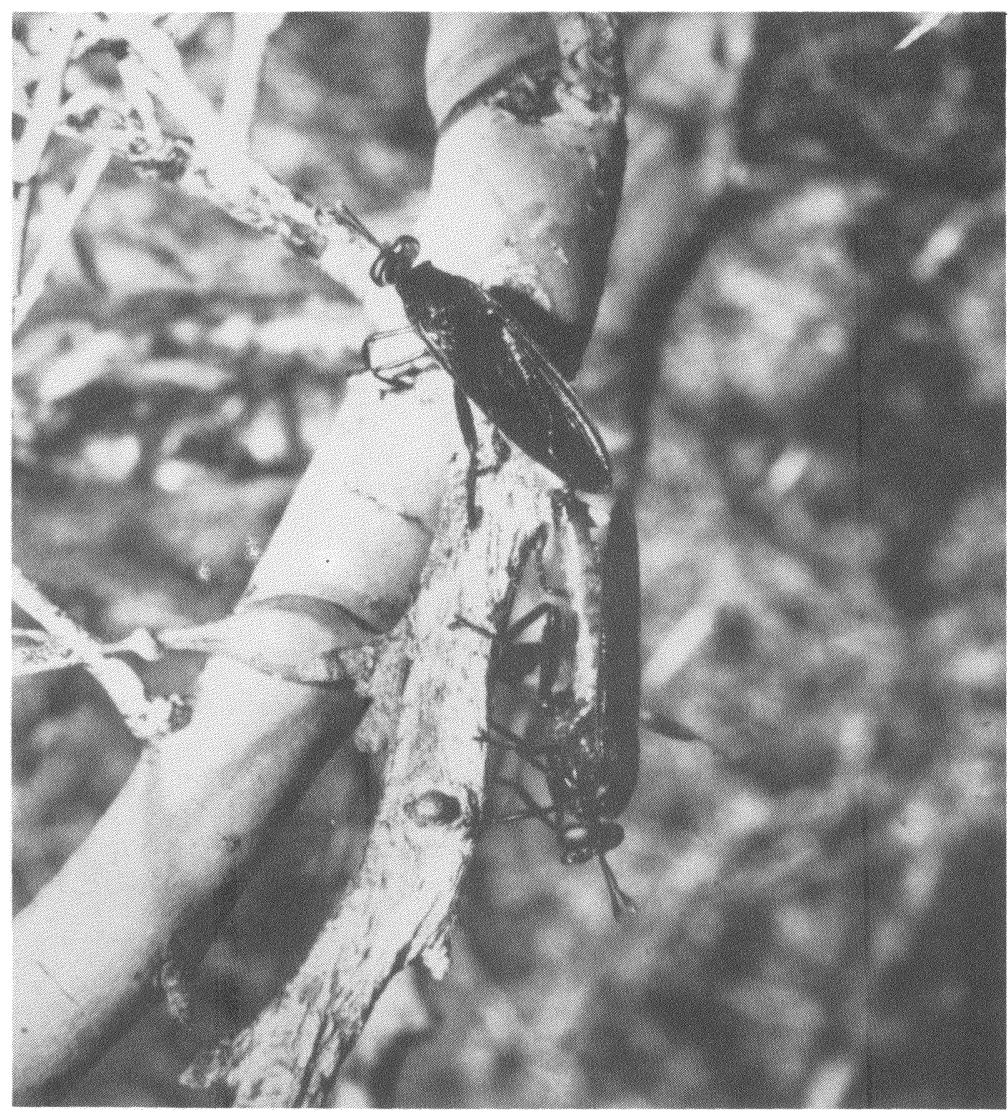

Fig. 2. A copulating pair of $M$. ventralis on the limb of a palo verde tree downslope from the ridgeline.

peak. The female was then released close to a perched male, which quickly captured her and initiated mating. I then netted the pair and separated them after they had copulated for less than $5 \mathrm{~min}$. The now-unpaired female was released near a second male. He too took the female in flight and copulated with her, suggesting that females may retain their receptivity for some time after the initiation of copulation.

Only two other unpaired females were seen at the peak for any length of time before mating. One was captured and marked at an elevated point at a time when the site lacked a resident male. The 
female traveled along the ridgeline and a short time later was found in copula with a male at another of the main male perching areas about $100 \mathrm{~m}$ distant. The other unpaired female appeared at a territory site when the resident male was copulating with an earlier arrival. The newcomer flew conspicuously in a large circle about the area and perched briefly before repeating the flight. She then flew off, traveling along the ridgeline toward another of the elevated points on the peaktop.

\section{Discussion}

The mydid fly $M$. ventralis is a moderately territorial hilltopping insect. Males perch at elevated points (landmarks) along a peaktop ridgeline. They pursue all manner of flying objects approximately the size of conspecifics. Other males are either chased off or "encouraged" to perch far from their pursuers. Members of other species are closely approached and then quickly abandoned; these species-identification checks are particularly often triggered by males of the scoliid wasp Triscolia ardens, which regularly patrol the ridgeline at Usery Peak. The wasp, like the mydid fly, possesses dark wings and a bright orange/red abdomen. Nelson (1986) also found that males of $M$. xanthopterus pursued a broad variety of flying insects, including wasps similar in appearance to the mydid fly.

Females of $M$. ventralis fly to landmark territories, where they circle about in slow and conspicuous loops, promptly stimulating an approach flight by any perched male in the area. Capture and copulation quickly follow. There is no evidence that females visit the peaktops for any purpose other than mating. The flies were never observed feeding, ovipositing, or emerging at the peaktop nor is the location of these activities known. It is typical of hilltopping insects that females are diffusely distributed and difficult to locate, suggesting that hilltopping is a default strategy (Bradbury, 1977, 1985) for males unable to find females at other economically defendable places.

The mating system of $M$. ventralis is extremely similar to that of M. xanthopterus (Nelson, 1986) involving early morning defense of peaktop perching areas. But why these two species should employ a hilltopping mating system, whereas other equally rare and sparsely 
distributed mydid flies in the same regions do not, is a continuing puzzle.

The mating system of $M$. ventralis has converged in some major respects with that of other unrelated hilltopping species. The locations selected by perching males are much the same as those adopted by a Cuterebra rodent botfly (Alcock and Schaefer, 1983) and are near prominent peaktop paloverde trees that are used as perch sites by many other hilltopping species, notably the tarantula hawk wasp Hemipepsis ustulata (Alcock, 1981; Alcock and Carey, 1988). The degree of female choice is the same in the wasp and mydid fly with females making themselves conspicuous to perching males and accepting the first male that captures them in flight. Thus, any selectivity by female of $M$. ventralis must be exercised in the choice of the landmark that they visit. By picking spots that are more strongly contested than others, females might improve their chances of mating with a male tested in combat by other males.

Unlike the tarantula hawk wasp, however, large body size in males does not appear to confer a competitive advantage in $M$. ventralis, a highly variable species in body size. Large male flies are no more likely to possess peaktop territories than small males, nor do they remain on station longer than their smaller rivals. In contrast, large male tarantula hawks can defeat smaller ones in aerial duels that can escalate into hour-long battles. As a result, large individuals eventually come to hold the perch territories most preferred by males (Alcock and Carey, 1988). In general, body size is a key determinant of success in aggressive disputes among insects, although there are numerous exceptions to the rule (Lederhouse, 1982; Thornhill and Alcock, 1983). Why large size should be advantageous in some but not all insect species is a question that remains to be answered.

Perhaps in $M$. ventralis there simply is not enough time for males to invest in aggressive interactions given that individuals occupy a territory for at most a few hours over a day or two. In contrast, males of the tarantula hawk $\mathrm{H}$. ustulata average eight days of territorial tenure, spending 5 to $6 \mathrm{hr}$ on their perches each day, before they are replaced (Alcock, 1981). Why the robust M. ventralis should have such a short life expectancy or such reduced site tenacity is yet another unresolved issue. The differences between the 
species confirm the general point that "hilltopping" mating systems are not all the same but include a considerable diversity of male mate-locating tactics (Alcock, 1987).

\section{ACKNOWLEDGMENTS}

This work was supported by NSF grant BNS 8620352. Nick Alcock assisted in field work. E. M. Fisher kindly identified the fly to species for me.

\section{REFERENCES}

ALCock, J.

1981. Lek territoriality in a tarantula hawk wasp Hemipepsis ustulata (Hymenoptera: Pompilidae). Behav. Ecol. Sociobiol. 8: 309-317.

1987. Leks and hilltopping in insects. J. Nat. Hist. 21: 319-328.

AlCOCK, J. AND M. CAREY

1988. Hilltopping behaviour and mating success of the tarantula hawk wasp, Hemispepsis ustulata (Hymenoptera: Pompilidae), at a high elevation peak. J. Nat. Hist. 22: 1173-1178.

Alcock, J. AND J. E. SchaEFER

1983. Hilltop territoriality in a Sonoran Desert bot fly (Diptera: Cuterebridae). Anim. Behav. 31: 518-525.

BRADBURY, J.

1977. Lek mating behavior in the hammer-headed bat. Z. Tierpsychol. 45 : 225-255.

1985. Contrasts between the insects and vertebrates in the evolution of male display, female choice, and lek mating. In B. Hölldobler and M. Lindauer, eds. Experimental Behavioural Ecology and Sociobiology. Gustav Fischer Verlag, Stuttgart. pp. 273-289.

CoLE, F. R.

1969. The Flies of Western North America. Berkeley, University of California Press.

EMLen, S. T. AND L. W. ORING

1977. Ecology, sexual selection and the evolution of mating systems. Science 197: 215-223.

LEDERHOUSE, R. C.

1982. Territorial defense and lek behavior of the black swallowtail butterfly, Papilio polyxenes. Behav. Ecol. Sociobiol. 10: 109-118.

NeLson, J. W.

1986. Ecological notes on male Mydas xanthopterus (Loew) (Diptera: Mydidae) and their interactions with Hemipepsis ustulata Dahlbohm (Hyme-

SHIELDS, 0. noptera: Pompilidae). Pan-Pac. Ent. 62: 316-322.

1967. Hilltopping. J. Res. Lepid. 6: 69-178. 
ThorNhill, R. AND J. AlCock.

1983. The Evolution of Insect Mating Systems. Cambridge, Harvard University Press.

Wilcox, J. AND N. PAPAVERo.

1971. The American genera of Mydidae (Diptera), with the description of three new genera and two new species. Arquiv. Zool. (Sao Paulo) 21: 41-119. 

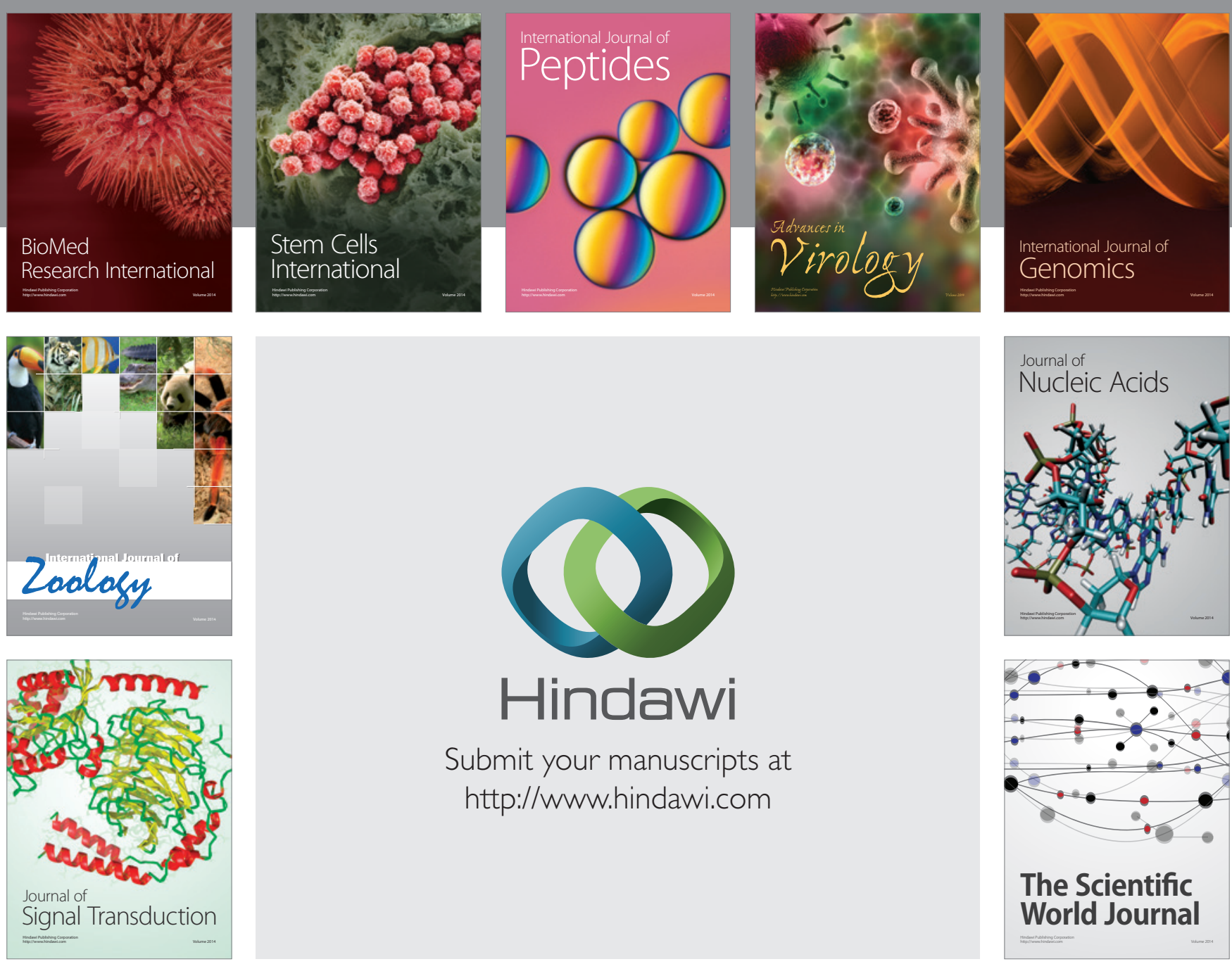

Submit your manuscripts at

http://www.hindawi.com
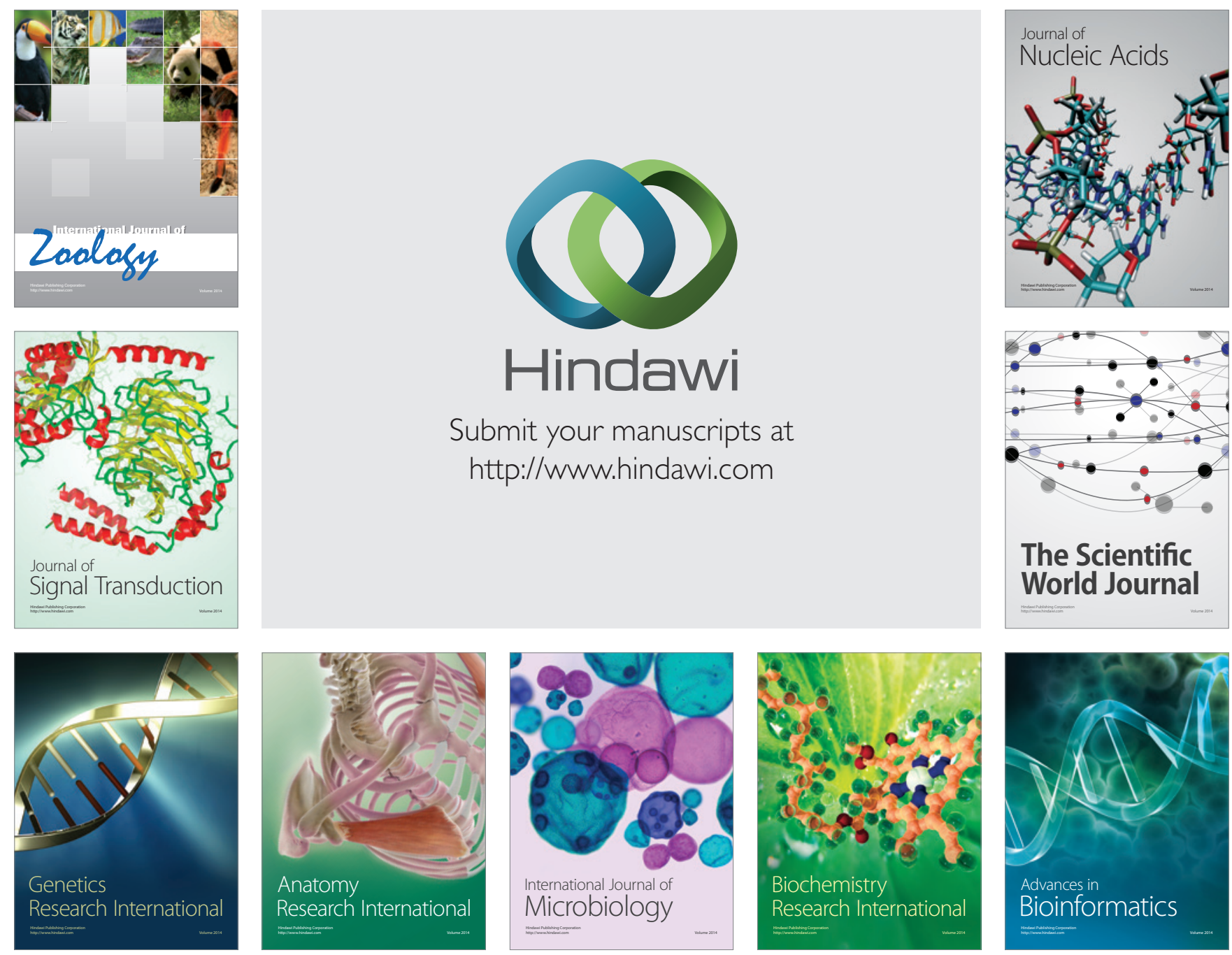

The Scientific World Journal
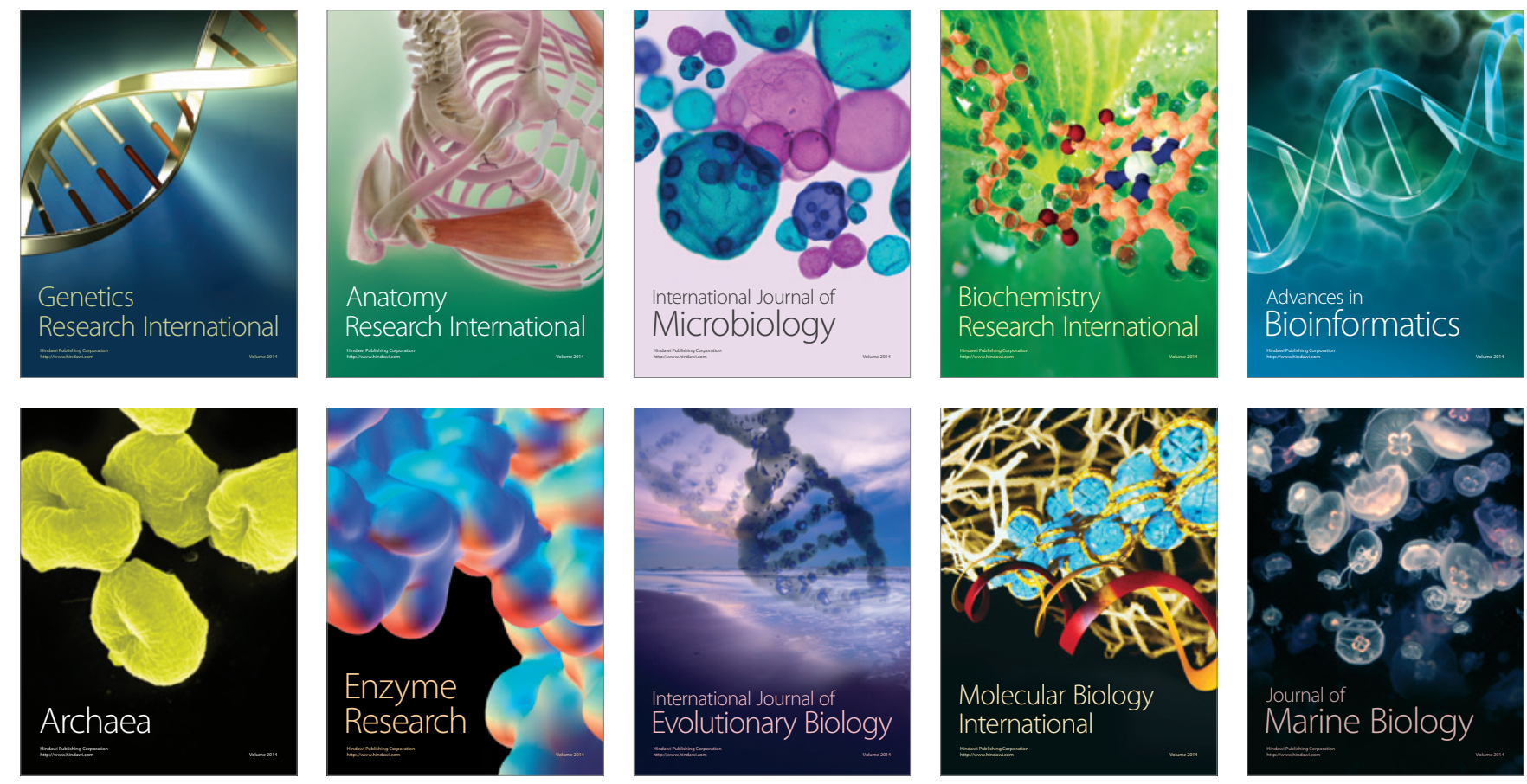